\title{
Chapter 9 \\ What if There Are No Laws? Emergence of Laws
}

The following speculations resemble Darwin's and also Turing's “inversion of reason" - that is, "competence without comprehension" - forcefully put forward by the atheistic philosopher Daniel Dennett in his phrase "delere Auctorem Rerum Ut Universum Infinitum Noscas; aka DARW(=UU)IN: destroy the author of things in order to know the universe".

\subsection{Mythological Roots}

The idea that the universe is lawless and grounded in Chaos, or a structureless void can be found in many mythologies and cosmogonies. For instance, in Chinese cosmogony hundun is identified with primordial chaos.

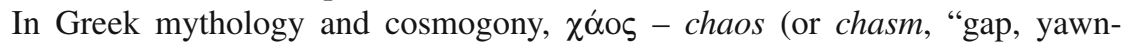
ing" [531, p. 3]) has been considered the primordial "nonform" of the universe. In

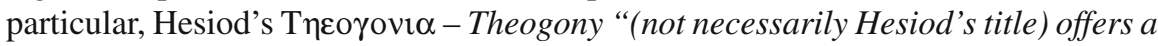
brief account of the origins of the cosmos as preface to the extolling of Zeus' rule", thereby contrasting the "lawful" organization of the world of the gods "with the absence of such order in previous times" [531, p. 1]: "From the beginning, tell me which of these was first to come. Chasm it was, in truth, who was the very first" [277, 115-116]; or, in a different translation, "In truth, first of all Chasm came to be" [276, 115-116]. The latter author remarks in Footnote 7: "Usually [[Chasm is]] translated as "Chaos"; but that suggests to us, misleadingly, a jumble of disordered matter, whereas Hesiod's term indicates instead a gap or opening."

Two centuries after Hesiod, Plato's Tomaeus stated that the god-demiurge "found everything visible in a state of turmoil, moving in a discordant and chaotic manner (prior to the intervention of the demiurge, there is chaos), so he led it from chaos to order, which he regarded as in all ways better" [412, p. 18,127; 30a]

Also the Bible's Genesis [1.2] states that, after its creation by God "the earth was without form and void." 


\subsection{Physical Indeterminism in Vienna at the Dawn of Quantum Mechanics}

Probably the first researcher speculating that all physical laws are not exact but emerge from, and are subject to, microphysical indeterminism, was Exner in fin de siècle Vienna: in his inaugural lecture "On Laws in Science and Humanities" as rector of the University of Vienna, held on October 15th, 1908, Exner suggests [209, p. 18] that there are no exact laws of nature; or, as Hanle puts it [262], "laws do not exist in nature but are formulated by man.” In Exner's own words [209], “. . . in the region of the small, in time as in space, the physical laws are probably invalid ... Therefore we have to perceive all so-called exact laws as probabilistic which are not valid with absolute certainty; but the more individual processes are involved the higher the certainty. All physical laws can be traced back to random processes on the molecular level, and from them the result follows according to the laws of probability theory..." 1

Indeed, Exner speculated, it could well be that the statistical laws do not necessitate nonprobabilistic, deterministic laws on the microlevel - it could well be that, in particular, on the microscopic level for individual particles, irreducible random events occur, giving rise to statistical macrolevel descriptions. Exner contemplates that this might be true even for classical physics such as collisions [209]. He also explicitly mentiones Boltzmann's methods of statistical physics.

Egon von Schweidler, a colleague of Exner at the University of Vienna, might have been the first to interpret single radioactive decays as irreducibly random [459] (cf. Chap. 15, p. 129). And Schrödinger, the "scientific apprentice" of both Schweidler and Exner, later in his inaugural lecture in Zürich (Antrittsrede an der Universität Zürich, 9. Dezember 1922 [451]; English translation in [454, Chap. VI, pp. 107118]), referred to Exner's indeterminism. So, essentially, both Exner's 1909 inaugural address as Rektor of the University of Vienna, as well as Schrödinger's 1922 inaugural address as chair professor for theoretical physics at the University of Zürich suggest the following: it is at least possible, if not preferable, to assume that all physical laws, classical and quantum alike, are emergent and correct only statistically and for large groups of outcomes, and at the microlevel are grounded in irreducible random individual events. As far as I know, these inaugural lectures are in German only and unavailable in their entirety in English; for excerpts and reviews see Refs. [262, 490-492].

\footnotetext{
${ }^{1}$ German original [209] “... im kleinen, der Zeit wie dem Raume nach, gelten die physikalischen Gesetze voraussichtlich nicht ... So müssen wir also alle sogenannten exakten Gesetze nur als Durchschnittsgesetze auffassen die nicht mit absoluter Sicherheit gelten, wohl aber mit um so größerer Wahrscheinlichkeit aus je mehr Einzelvorgängen sie sich ergeben. Alle physikalischen Gesetze gehen zurück auf molekulare Vorgänge zufälliger Natur und aus ihnen folgt das Resultat nach den Gesetzen der Wahrscheinlichkeitsrechnung. ...
} 


\subsection{Contemporary Representations}

Let us, for the sake of exposing an extreme position, contemplate on an infinite universe consisting of random bits - that is, these collection of bits are not only "lawless" in the sense that there does not exist any algorithm generating them, but they are, in a strictly formal way [103, 133, 355], also algorithmically incompressible. That is, its behaviour cannot be "compressed" by any algorithm or rule. One model of such a universe would be a single random real. We assume that the algorithmic incompressibility of encoded microphysical structures might be a quite appropriate formalization of primordial chaos.

There are two ways how pseudo-lawfulness might be "revealed" to intrinsic observers:

(i) Lawful substructures: It might be the case that these observers might have only restricted operational access to the entire random string, and merely perceive an orderly partial sequence (string) - that is, they accidentally live in a substructure of the random real which appears to be algorithmically compressible. Any such compression might be interpreted as a "law" governing this particular section of the universe.

Calude, Meyerstein and Salomaa discuss universes which are lawless [106, 114] and mention the possibility that we might be riding on a huge but finite segment of a random string which, to its inhabitants, appears to be lawful: "As our direct information refers to finite experiments, it is not out of question to discover local rules, functioning on large, but finite scales, even if the global behaviour of the process is truly random” [106, p. 1077].

These considerations are based on the finding that, "almost all real numbers, when expressed in any base, contain every possible digit or possible string of digits" [103, Theorem 6.1, p. 148] - even entire deterministic universes. There appear "spurious correlations" in the following sense: "very large databases have to contain arbitrary correlations. These correlations appear only due to the size, not the nature, of data" [113].

Yanofsky [581] has discussed related scenarios, and has heuristically investigated the "extracted order that can be found in the chaos" by considering large matrices and finding patterns therein: Suppose, instead of a matrix, a long string (one might say a $1 \times n$ matrix) whose entries are filled randomly and independently with decimal digits. The expected number of times any particular substring of $m$ digits, say " $123 \ldots m$," occurs within this larger string of length $n$ is $(n-m+1)(1 / 10)^{m}$.

(ii) Emergence: The laws of nature might actually be "emergent" in a Ramsey-theory type way. Because just as "one cannot not communicate" [562, Sect. 2.24, p. 51] Ramsey theory [248, 327, 476] reveals that there exist properties and correlations for any kind of data, which do not depend on the way these date are generated or structured. This would also (but is not limited to) include $\chi$ óos; that is, universes which are not "lawful" and not generated by intent; and consisting of data which cannot be algorithmically compressed. Such inevitable correlations might be 
"interpreted" as "laws" in any data: any sufficiently large structure inevitably contains orderly substructures which can be conjectured to be "lawful" - just as the Elders looked up into the skies and "found" animal constellations there [247]. Unlike the lawful substructures scenario, emergence does not presume local non-typicality.

\subsection{Provable Impossibility to Prove (In)Determinism}

Every absolute claim of both irreducible determinism and indeterminism remains speculative and metaphysical. Because, due to the recursive undecidability of induction (the rule inference), one can never be sure if a phenomenology identified as deterministic - with a particular law or "theory of everything" [34] - "switches its course" and behaves differently, thereby disproving such claims. This is ultimately due to the fact that no recursive upper (algorithmic space/memory and runtime) bound exists for such an assertion.

Conversely, any claim of absolute, irreducible indeterminism falls short of a proof that no laws exist relative to the phenomenology; for various reasons. Suppose the physical phenomena are coded into bit strings; then these bit strings are necessarily finite (there is no infinite operational precision). For finite bit strings always laws exist - think of a simple enumeration. One may also argue that, due to reduction from the halting problem, it cannot be guaranteed that no algorithmic compression exists - in general this bound will also be proportional to the worst-case scenario, which is a busy beaver type behaviour [128] - and thus nonrecursive in the length of the bit string. And finally, and also connected with worst-case space/memory and runtime - not all laws can in principle be enumerated (because there exist a potential infinity of them); and those few analized cannot be recursively asserted to not yield that particular bit string encoding the aforementioned phenomenology.

\subsection{Potential Misperceptions by Over-interpretation}

Square-integrable functions can be approximated by a variety of rather different complete systems of orthogonal functions [18, Sect. 10.4, p. 649], such as, for instance, trigonometric functions, (Legendre) polynomials, or, more generally, due to the spectral theorem the system of eigenfunctions of certain normal operators. Are we thus justified to infer that such a particular function, because it can be written in these various forms, is actually "composed of," say, vibrations and oscillations in the case of Fourier analysis, or, alternatively, polynomials, or any other such complete set of orthogonal functions? At first sight it might be tempting to assume just that. But a second thought reveals that these choices of functional sets (and thus of normal operators) are purely conventional. They might, from the practical point of view, be 
Fig. 9.1 Ironic example of an over-interpretation of an image

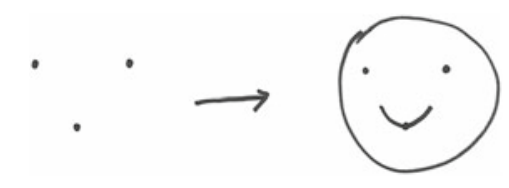

convenient or suitable fapp, but they cannot justify any "deep" truth or ontology. They are just particular formal representations of a functional entity.

As has been noted already in the preface, in order to cope with subjective projections of the mind, as well as with wishful thinking, Freud advised analysts to adopt a contemplative strategy of evenly-suspended attention [224, 225]; and, in particular, to be aware of the dangers caused by "... the temptation of projecting outwards some of the peculiarities of his own personality, which he has dimly perceived, into the field of science, as a theory having universal validity; he will bring the psycho-analytic method into discredit, and lead the inexperienced astray." [224] ${ }^{2}$ And the late Jaynes warns and disapproves of the Mind Projection Fallacy [290, 291], pointing out that "we are all under an ego-driven temptation to project our private thoughts out onto the real world, by supposing that the creations of one's own imagination are real properties of Nature, or that one's own ignorance signifies some kind of indecision on the part of Nature."

For a recent neurophysiological finding corroborating the possibility to induce hallucinations by perceptual priors and expectations see Ref. [419].

So, it may not be entirely unreasonable to speculate that our own universe might be grounded in $\chi \alpha$ óo - chaos (or chasm, "gap, yawning" [531, p. 3]). Those "laws" which we purport to "discover" might be spurious reflections of our own minds, desperately attempting to "make sense" of the phenomena.

One is reminded of Fritz Lang's remark in Godard's movie Le mépris (Contempt), approximately 14 min into that movie: “Jerry, don't forget. The gods have not created man. Man has created gods." And Schrödinger, in Nature and the Greeks, quotes fragments of Xenophanes as follows [456, p. 71]: “(Fr. 15) Yes, and if the oxen or horses or lions had hands and could paint with their hands, and produce works of art as men do, horses would paint the forms of the gods like horses, and oxen like oxen and make their bodies in the image of their several kinds. (Fr. 16) The Ethiopians make their gods black and snubnosed; the Thracians say theirs have blue eyes and red hair."

For the sake of a bold demonstration take some recent findings in machine learning. In particular, consider the interpretation of photographic images by neural networks, also called deep dreaming. Depending of the class of objects the network has handled and has been trained to recognize in the past, it "projects" or interprets images presented to it according to its expectations and (trained) knowledge. Thereby [374],

\footnotetext{
${ }^{2}$ German original [225]: "Er wird leicht in die Versuchung geraten, was er in dumpfer Selbstwahrnehmung von den Eigentümlichkeiten seiner eigenen Person erkennt, als allgemeingültige Theorie in die Wissenschaft hinauszuprojizieren, er wird die psychoanalytische Methode in Misskredit bringen und Unerfahrene irreleiten".
} 
"even a relatively simple neural network can be used to over-interpret an image, just like as children we enjoyed watching clouds and interpreting the random shapes." An ironic and less sophisticated example is graphically depicted in Fig. 9.1.

Open Access This chapter is licensed under the terms of the Creative Commons Attribution 4.0 International License (http://creativecommons.org/licenses/by/4.0/), which permits use, sharing, adaptation, distribution and reproduction in any medium or format, as long as you give appropriate credit to the original author(s) and the source, provide a link to the Creative Commons license and indicate if changes were made.

The images or other third party material in this chapter are included in the chapter's Creative Commons license, unless indicated otherwise in a credit line to the material. If material is not included in the chapter's Creative Commons license and your intended use is not permitted by statutory regulation or exceeds the permitted use, you will need to obtain permission directly from the copyright holder.

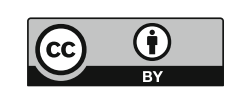

